Check for updates

Cite this: RSC Adv., 2019, 9, 15703

\title{
On the homocoupling of trialkylstannyl monomers in the synthesis of diketopyrrolopyrrole polymers and its effect on the performance of polymer- fullerene photovoltaic cells
}

\begin{abstract}
Gaël H. L. Heintges ${ }^{\mathrm{ab}}$ and René A. J. Janssen (D) *ac
Homocoupling of monomers in a palladium-catalyzed copolymerization of donor-acceptor polymers affects the perfect alternating structure and may deteriorate the performance of such materials in solar cells. Here we investigate the effect of homocoupling bis(trialkylstannyl)-thiophene and -bithiophene monomers in two low band gap poly(diketopyrrolopyrrole-alt-oligothiophene) polymers by deliberately introducing extended oligothiophene defects in a controlled fashion. We find that extension of the oligothiophene by one or two thiophenes and creating defects up to at least $10 \%$ does not significantly affect the opto-electronic properties of the polymers or their photovoltaic performance as electron donor in solar cells in combination with $[6,6]$-phenyl $C_{71}$ butytic acid methyl ester as acceptor. By using model reactions, we further demonstrate that for the optimized synthetic protocol and palladiumcatalyst system the naturally occurring defect concentration in the polymers is expected to be less than $0.5 \%$.
\end{abstract}

Received 9th April 2019

Accepted 13th May 2019

DOI: $10.1039 / c 9 r a 02670 c$

rsc.li/rsc-advances

\section{Introduction}

The performance of conjugated polymers in organic solar cells is primarily determined by the chemical structure of the backbone and side chains that provide the material with its semiconducting and structural properties. However, other factors such as the molecular weight distribution, ${ }^{1-3}$ the presence of end groups, ${ }^{4,5}$ possible branching of the main chain, ${ }^{6}$ and impurities in the polymer can also affect the functional properties. $^{7-9}$ In addition, structural defects in the polymer main chain have been found to be important. For asymmetric monomers head-to-head or tail-to-tail couplings may occur, next to the preferred head-to-tail linkages. ${ }^{\mathbf{1 0 , 1 1}}$ Alternatively, in the case of crosscoupling polymerizations where two complementary comonomers are used, a coupling reaction between two identical monomers introduces a defect in the perfect alternating structure. This last phenomenon is referred to as homocoupling. Homocoupling reactions are known to occur in the Suzuki, ${ }^{12}$ Stille, ${ }^{\mathbf{1 3}}$ and direct arylation ${ }^{\mathbf{1 4}}$ crosscoupling polycondenstation reactions that are commonly used to synthesize donor-acceptor small-molecules and polymers that find

${ }^{a}$ Molecular Materials and Nanosystems, Institute for Complex Molecular Systems, Eindhoven University of Technology, P. O. Box 513, 5600 MB Eindhoven, The Netherlands. E-mail: r.a.j.janssen@tue.nl

${ }^{b}$ Institute for Materials Research (IMO-IMOMEC), Design \& Synthesis of Organic Semiconductors (DSOS), Hasselt University, Agoralaan, 3590 Diepenbeek, Belgium

${ }^{c}$ Dutch Institute for Fundamental Energy Research, De Zaale 20, 5612 AJ Eindhoven, The Netherlands widespread use organic solar cells. The topic of structural defects is finding increasing awareness and was recently reviewed by Maes et al. ${ }^{15}$

The homocoupling of two bromide monomers in the Suzuki and Stille polymerization reaction in low band gap diketopyrrolopyrrole (DPP) polymers has previously been investigated in our group in some detail. ${ }^{16}$ The defect is caused by homocoupling of two brominated dithienyl-diketopyrrolopyrrole (TDPP-T) units, creating T-DPP-2T-DPP-T defects in the polymer main chain. These defects generate a low-energy feature in the absorption spectrum. As a result the $2 \mathrm{~T}$ defect can act as a trap for excitons and charges, and thereby explains the significant decrease in photovoltaic performance of solar cells when polymers with increasing $2 \mathrm{~T}$ defect concentration were blended with $[6,6]$-phenyl $\mathrm{C}_{71}$ butyric acid methyl ester ([70]PCBM). ${ }^{16}$ An extensive overview of the literature showed that the same homocoupling defect is present in many DPP polymers that were reported up to $2014 .{ }^{\mathbf{1 6}}$ We found it to occur when a too low ligand-to-palladium ratio is used in the reaction and that it can largely be avoided by modifying the catalyst system. The results also clearly demonstrated that this type of defect should be avoided because it is detrimental to the photovoltaic performance of these materials.

In a subsequent study $\mathrm{Li}$ et al. confirmed the formation of TDPP-2T-DPP-T low-energy defects occurring in the Stille polymerization of poly(diketopyrrolopyrrole-alt-quaterthiophene) (PDPP4T). ${ }^{17}$ Li et al. also suggested that homocoupling of the trilalkylstannyl monomers would occur to a significant extent. ${ }^{17}$ 
They were unable to obtain direct structural or spectroscopic evidence, but argued that because of the almost quantitative reaction yield of the polymerization, the two different homocoupling reactions should occur to a similar extent. In a recent study, Costantini et al. used scanning tunneling microscopy to investigate structural defects in poly(diketopyrrolopyrrole-altterfurane) (PDPP3F) deposited on a Au(111) surface. They found a significant amount ( $c a .12 \%$ ) of defects in which an extra furan ring is present as result of homocoupling reaction between two 2,5-bis(trimethylstannyl)furan monomers. ${ }^{18}$ Coupling of the trialkylstannyl monomers in a Stille cross-coupling polymerization reaction can occur whenever palladium is existent in an oxidized form. ${ }^{19-22}$ This oxidized palladium can be present in the reaction mixture due to the age or improper storage of the catalyst, insufficient degassing of the reaction mixture, or because the catalyst system is designed as such, as is in the case of bis(triphenylphosphine)palladium(II) dichloride. In these cases a double transmetallation step occurs, followed by a reductive elimination transforming the $\operatorname{Pd}(\mathrm{II})$ into a $\operatorname{Pd}(0)$ species, which can then proceed to catalyze the reaction as usual, and results in a coupling between two organometallic partners.

Recently, Sommer et al. investigated this type of homocoupling in poly $\left(N-9^{\prime}\right.$-heptadecanyl-2,7-carbazole-alt-5,5-( $4^{\prime}, 7^{\prime}$-di-2thienyl-2', $1^{\prime}, 3^{\prime}$-benzothiadiazole)) (PCDTBT) polymers synthesized via a Suzuki reaction and found that the homocoupling of the boronic ester substituted carbazole monomers resulted in a remarkably lower performance in organic solar cells from defect concentrations as low as $2.4 \%$ onwards. ${ }^{23}$ Whether this decrease was due to electronic or morphological effects was, however, not very clear.

In DPP polymers, the effect of extended donor segment defects has not yet been systematically investigated, even though its occurrence, for the reasons mentioned above, can be expected. Usually, DPP donor-acceptor polymers are synthesized in Stille coupling reactions employing a dibromide monomer containing the electron-deficient DPP unit and a bis(trialkylstannyl) monomer comprising the electron-rich moiety. The reason for this choice is that oxidative addition is facilitated by electron withdrawing groups and transmetalation is facilitated by electron rich organotin compounds. Hence, homocoupling of the organotin compounds typically results in extended electron-rich segments in the polymer. ${ }^{24}$ These can have two distinct effects. First, the energy levels of the polymer might be affected, because the extended donor defect can have energy levels that deviate from those of the polymer and cause a shift of the oxidation potential. Depending on the direction of this shift of the energy levels, the defects can act as traps and contribute to an increased non-radiative recombination which lowers the open-circuit voltage $\left(V_{\mathrm{OC}}\right)$ of the cells. Because DPP polymers usually display a wider optical band gap $\left(E_{\mathrm{g}, \mathrm{opt}}\right)$ when the donor block is extended, it is not expected that these defects will form energetic traps, although optical effects could still be visible. Second, the homocoupling defect effectively reduces the number DPP units in the chain that generally carry the solubilizing side chains, such that the solubility could be affected. This could have an influence on the morphology of the active layers, resulting in differences in short-circuit current $\left(J_{\mathrm{sc}}\right)$ or fill factor $(\mathrm{FF}){ }^{3}$

Here we investigate the effect and extent of the homocoupling reaction of the trialkylstannyl monomers in two archetype DPP polymers by deliberate introduction of defected conjugated segments and by performing model reactions on monomer analogs. As it is a frequently used monomer, thiophene and its defect, bithiophene, are chosen initially. In a second example, the structural difference between the parent polymer and its homocoupling defect is enhanced by using bithiophene and its defect, quaterthiophene, as monomer. We demonstrate that for these polymers, this type of homocoupling does not occur to a significant extent and that if it would occur, the effects on the opto-electronic properties and photovoltaic performance are small or even absent.

\section{Results and discussion}

\subsection{Poly(diketopyrrolopyrrole-alt-terthiophene) with quaterthiophene defects}

Poly $\left\{2,2^{\prime}\right.$-[(2,5-bis(2-hexyldecyl)-3,6-dioxo-2,3,5,6-tetrahydropyrrolo[3,4-c]pyrrole-1,4-diyl)dithiophene]-5,5'-diyl-altthiophen-2,5-diyl\} (PDPP3T) is a well-known small band gap DPP polymer used for high-performing organic field-effect transistors and solar cells and a good model system to investigate the effect of homocoupling. To simulate the homocoupling of two trialkylstannyl monomers, a random terpolymer approach was used in which 3,6-bis(5-bromothiophen-2-yl)-2,5bis(2-hexyldecyl)-2,5-dihydropyrrolo[3,4-c]pyrrole-1,4-dione (1) was co-polymerized with 2,5-bis(trimethylstannyl)thiophene (2) and 5,5'-bis(trimethylstannyl)-2,2'-bithiophene (3) in varying ratios (Scheme 1). This resulted in PDPP3T polymers with 5, 10, and $20 \%$ of $4 \mathrm{~T}$ defects added in the chain.

Gel permeation chromatography (GPC) in 1,2-dichlorobenzene $\left(o\right.$-DCB) at $140{ }^{\circ} \mathrm{C}$ revealed a decreasing trend in the number average molecular weight $\left(M_{\mathrm{n}}\right)$ from 148 to $88 \mathrm{kDa}$ when increasing the amounts of $4 \mathrm{~T}$ defects from $5 \%$ to $20 \%$ (Table 1). Several reasons can explain a reduced $M_{\mathrm{n}}$. We tentatively ascribe this trend to a decrease in solubility with increasing defect content. As mentioned above, the $4 \mathrm{~T}$ segments effectively dilute the sidechain-bearing DPP units in the main chain. This lowers the solubility and may cause the polymers above a certain length to precipitate out of solution during the polymerization. To fairly compare the defect containing polymers with defect-free PDPP3T, two batches of differing molecular weight were chosen corresponding roughly to the molecular weights obtained in defect containing polymers.

The UV-vis-NIR absorption spectra of the PDPP3T polymers measured in solution and thin films (Fig. 1) show no differences in shape of the absorption or optical band gap as function of the number of defects. When compared to an essentially defect-free PDPP3T, a difference in absorption maximum is visible in the solution spectra. This could be due to a different tendency towards aggregation in solution, and would suggest that the defect-free PDPP3T aggregates more than the defect-containing polymers. The shift in absorption maximum is, however, 


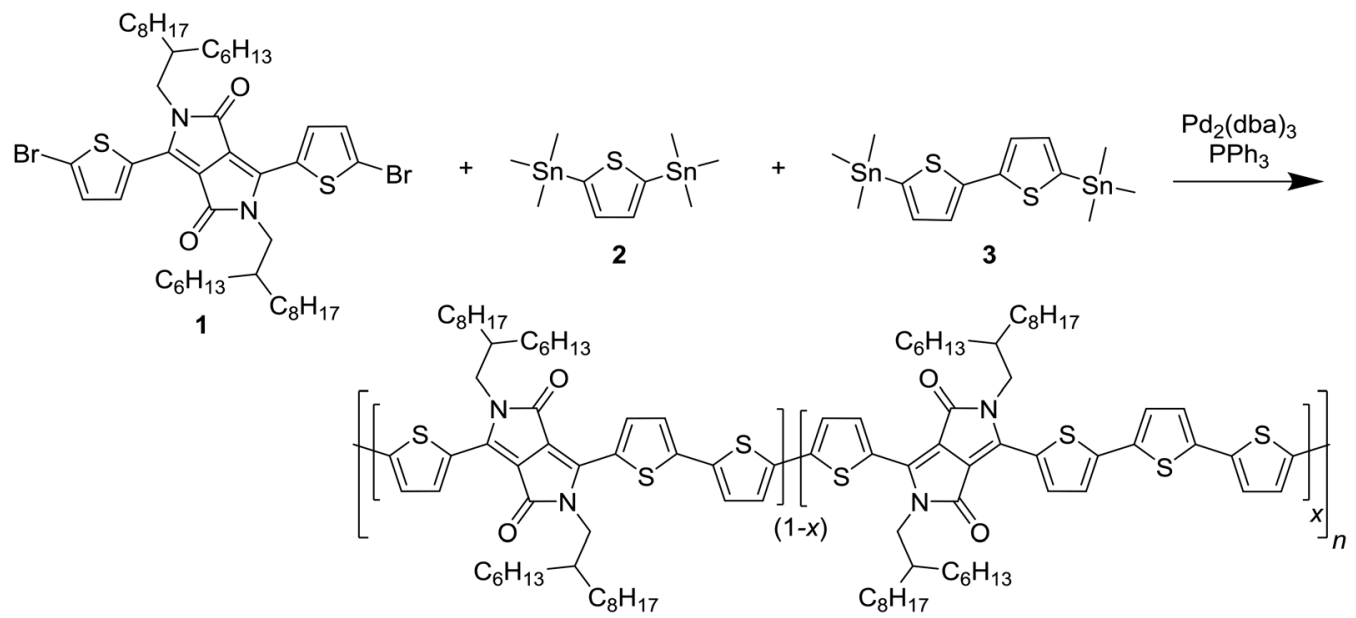

Scheme 1 Synthesis of the PDPP3T polymers with 4T defects. The stoichiometry of monomers 2 and 3 was altered to obtain $x=5,10$, and $20 \%$ of intentional defects.

unlikely to be linked to the electronic nature of the defects as between varying levels of $4 \mathrm{~T}$ defects no difference can be seen. We note that the signal at $\sim 400 \mathrm{~nm}$, which is assigned to a transition to a higher-energy state, shows a gradual shift from $3.06 \mathrm{eV}$ for PDPP3T, via $3.07(5 \% 4 \mathrm{~T})$ and 3.01 (10\% 4T), to $2.98 \mathrm{eV}(20 \% 4 \mathrm{~T})$ when the defect level is increased. Such small shift with extending the donor segment is also seen in the corresponding small molecule compounds T-DPP-3T-DDP-T and T-DPP-4T-DDP-T where the corresponding peaks are found at $3.16 \mathrm{eV}$ for the $3 \mathrm{~T}$ derivative and at $3.10 \mathrm{eV}$ for the $4 \mathrm{~T}$ derivative. In thin films the differences are also small. Because the optical band gap of PDPP4T (the defect segments) is at $1.46 \mathrm{eV}$ (vide infra) and larger than the band gap of PDPP3T at $1.33 \mathrm{eV}$, the presence of $4 \mathrm{~T}$ segments will unlikely result in a clear change of the absorption spectrum and $4 \mathrm{~T}$ defects are not expected to influence the optical band gap.

Square wave voltammetry was used to determine the energy levels of the polymers. Table 1 reveals there are no significant differences in energy levels between the polymers. Again, 4T defects are also not expected to exert a strong effect because the HOMO and LUMO energy levels of PDPP4T (HOMO: $-5.13 \mathrm{eV}$, LUMO: $-3.26 \mathrm{eV}$ ) are not too dissimilar from those of PDPP3T (HOMO: $-5.14 \mathrm{eV}$, LUMO: $-3.34 \mathrm{eV}$ ).

Solar cells with an ITO/PEDOT:PSS/active layer/LiF/Al device configuration were produced by spin coating mixed solutions of the PDPP3T polymers and [70]PCBM $(1: 2 \mathrm{w} / \mathrm{w})$ in chloroform containing 7.5\% of $o$-DCB. As can be seen in Table 2 and Fig. 2 there are no clear trends in the PCEs of the defect-containing polymers. They all perform slightly worse than PDPP3T for a similar $M_{\mathrm{n}}$. The $V_{\mathrm{oc}}$ of the defect-containing polymers lies between $0.65 \mathrm{~V}$ and $0.67 \mathrm{~V}$, which coincides with range generally observed for defect-free PDPP3T. This indicates, in accordance with the results from the square wave voltammetry, that this type of defect has little to no influence on the energy levels of the polymer and therefore does not affect the $V_{\mathrm{oc}}$. The fill factors lie between 0.64 and 0.68 , and are also comparable with the FF of defect-free PDPP3T cells. This indicates that the $4 \mathrm{~T}$ segments do not strongly increase the recombination of free charges, which is concurrent with the notion that these defects do not act as energetic traps.

The main difference between the cells listed in Table 2 occurs in the $J_{\mathrm{sc}}$. When comparing the $20 \%$ defect polymer with the low $M_{\mathrm{n}}$ defect-free PDPP3T batch, a slightly lower $J_{\mathrm{sc}}$ is found, even though the molecular weights are comparable. The same is the case in the comparison between the $5 \%$ defect polymer and the high $M_{\mathrm{n}}$ defect-free PDPP3T batch. Taken separately, these observations could suggest that the homocoupling defects negatively influence the $J_{\text {sc }}$ of the solar cells. However, this conclusion is weakened when considering the lack of a trend in $J_{\mathrm{sc}}$ with increasing amounts of defects. If defects negatively influence $J_{\mathrm{sc}}$, the $10 \%$ defect polymer would be expected to have a lower $J_{\mathrm{sc}}$ than the $5 \%$ defect polymer, both on account of the higher amount of $4 \mathrm{~T}$ segments and the lower $M_{\mathrm{n}}$. This is, however, not the case and leads to the conclusion

Table 1 Physical properties of the PDPP3T polymers with different defect ratios

\begin{tabular}{lllllrr}
\hline Polymer & $M_{\mathrm{n}}[\mathrm{kDa}]$ & $M_{\mathrm{w}}[\mathrm{kDa}]$ & $D$ & $E_{\mathrm{g}, \mathrm{opt}^{a}[\mathrm{eV}]}$ & $\mathrm{HOMO}^{b}[\mathrm{eV}]$ & -5.14 \\
\hline PDPP3T & 147 & 400 & 2.7 & 1.33 & -3.34 \\
& 68 & 255 & 3.7 & & -5.13 & -3.35 \\
$5 \% 4 \mathrm{~T}$ & 148 & 399 & 2.7 & 1.35 & -5.03 & -3.35 \\
$10 \% 4 \mathrm{~T}$ & 123 & 330 & 2.7 & 1.36 & -3.10
\end{tabular}

${ }^{a}$ Determined from the absorption onset in thin films. ${ }^{b}$ Determined with square wave voltammetry $v s . \mathrm{Fc} / \mathrm{Fc}^{+}$, which was set at $-4.8 \mathrm{eV} v s$. vacuum. 



Fig. 1 UV-vis-NIR spectra of PDPP3T polymers with 4T defects. (a) Dissolved in chloroform. (b) In thin films.

Table 2 Photovoltaic performance of the PDPP3T polymers with 4T defects $^{a}$

\begin{tabular}{llllll}
\hline Polymer & $M_{\mathrm{n}}[\mathrm{kDa}]$ & $J_{\mathrm{sc}}\left[\mathrm{mA} \mathrm{cm}^{-2}\right]$ & $V_{\mathrm{oc}}[\mathrm{V}]$ & $\mathrm{FF}$ & PCE [\%] \\
\hline PDPP3T & 147 & $15.4(15.3)$ & $0.67(0.66)$ & $0.69(0.68)$ & $7.1(6.9)$ \\
PDPP3T & 68 & $13.6(13.5)$ & $0.65(0.65)$ & $0.66(0.66)$ & $5.9(5.8)$ \\
$5 \% 4 \mathrm{~T}$ & 148 & $13.4(14.1)$ & $0.67(0.66)$ & $0.68(0.64)$ & $6.1(6.0)$ \\
$10 \% 4 \mathrm{~T}$ & 123 & $14.6(14.6)$ & $0.66(0.65)$ & $0.66(0.65)$ & $6.4(6.2)$ \\
$20 \% 4 \mathrm{~T}$ & 88 & $12.4(12.5)$ & $0.65(0.65)$ & $0.67(0.66)$ & $5.4(5.3)$
\end{tabular}

${ }^{a}$ Best cells are shown, numbers between parentheses refer to the average over 4 cells.

that these differences in $J_{\mathrm{sc}}$ are most likely caused by other factors such as molecular weight and nanomorphology and that the possible influence of the $4 \mathrm{~T}$ defects, even in quite large concentrations ( $10 \%$ and $20 \%$ ), is small enough to be eclipsed by other effects.

\subsection{Poly(diketopyrrolopyrrole-alt-quaterthiophene) with sexithiophene defects}

To introduce a larger defect, PDPP4T was chosen as the next target for modification. PDPP4T can be synthesized in polymerization of a dibrominated DPP monomer such as $\mathbf{1}$ and 5,5'-bis(trimethylstannyl)-2,2'-bithiophene (3). The associated homocoupling defect would them be a $6 \mathrm{~T}$ segment. Introducing 6T segments in PDPP4T in a fashion analogous to Scheme 1 proved to be a synthetic challenge, owing to the difficulty of obtaining a bis(trialkylstannyl) derivative of the unsubstituted quaterthiophene. It was therefore decided to asymmetrically extend a DPP monomer. By reacting 3-(5-bromothiophen-2-yl)2,5-bis(2-decyltetradecyl)-6-(thiophen-2-yl)-2,5-dihydropyrrolo [3,4-c]pyrrole-1,4-dione (4) with 2-([2,2'-bithiophen]-5-yl)-4,4,5,5tetramethyl-1,3,2-dioxaborolane (5) it was possible to obtain $\mathbf{6}$, which was converted by bromination with $N$-bromosuccinimide into 7 as shown in Scheme 2. We used long 2-decyltetradecyl side chains on the DPP unit in 4 to ensure sufficient solubility of the extended monomer 7 and of the resulting PDPP4T polymers.

This asymmetrically extended DPP monomer 7 introduces the possibility of creating $8 \mathrm{~T}$ segments, even in the absence of homocoupling reactions. To keep this possibility small and to keep the defect concentration within levels which are expected to occur during a normal polymerization reaction, polymers with $2 \%$ and $5 \%$ of defects were synthesized, together with defect-free PDPP4T as a reference, as shown in Scheme 3.
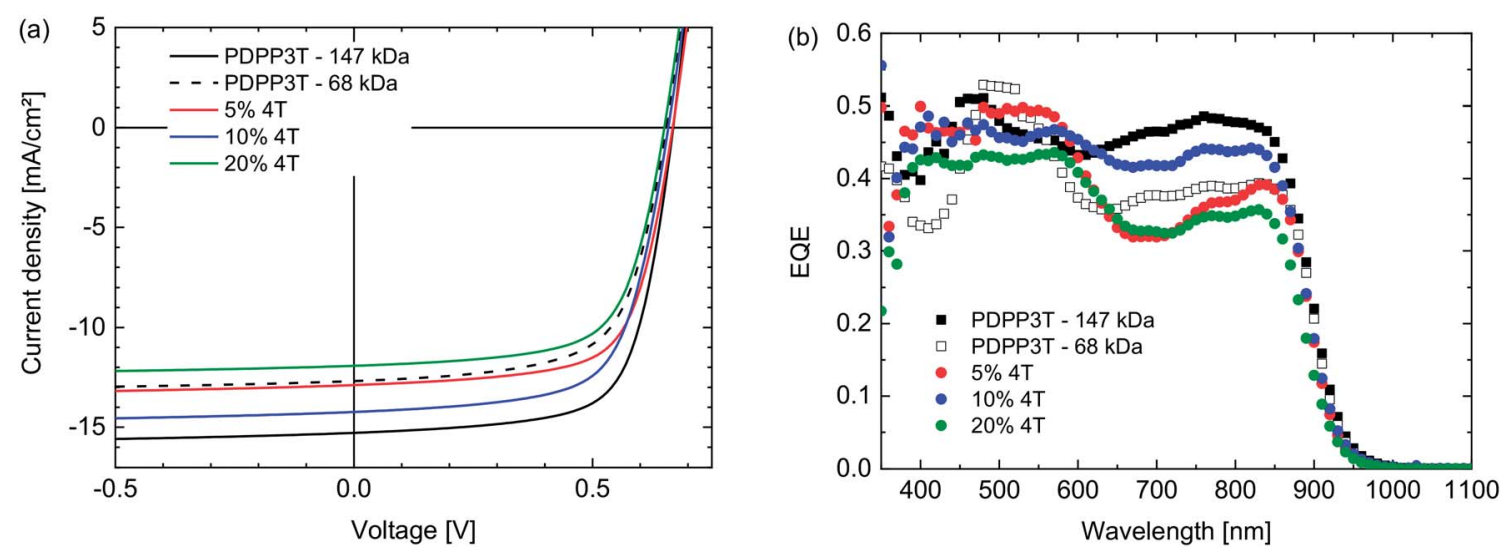

Fig. 2 (a) J-V-characteristics of PDPP3T : [70]PCBM (1:2 w/w) polymer solar cells in which the PDPP3T polymers contain 4T defects (see legends). (b) Corresponding EQE spectra. 


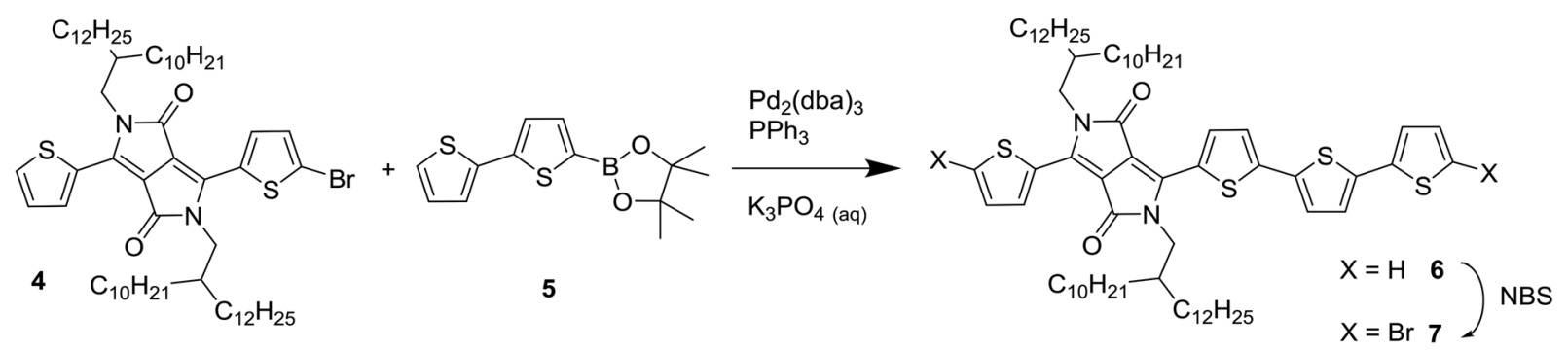

Scheme 2 Synthesis of the asymmetrically extended monomer 7 to introduce 6T defects in a PDPP4T polymer.

GPC analysis in $o$-DCB at $140{ }^{\circ} \mathrm{C}$ revealed comparable molecular weights for the three PDPP4T polymers, which should allow for a more direct comparison of the materials and enable to observe the effects of the $6 \mathrm{~T}$ segments more clearly.

The UV-vis-NIR absorption spectra showed no significant difference between the three polymers (Fig. 3). In thin films the optical band gap is at $1.46 \mathrm{eV}$ (Table 3). It is not expected that 6T segments would have a lower optical band gap than the $4 \mathrm{~T}$ segments, because the optical band gap of a PDPP6T polymer of $1.48 \mathrm{eV}$ (ref. 25) is close to that of PDPP4T (1.46 eV). Analysis of the HOMO and LUMO energy levels with square wave voltammetry also revealed no significant differences (Table 3). As in the case of PDPP3T, the defects seem to have no important influence on the electronic structure of the materials.

Solar cells were made from a chloroform solution containing $10 \% o$-DCB, using the PDPP4T polymers and [70]PCBM $(1: 2 \mathrm{w} /$ w) as active layer, employing the ITO/PEDOT:PSS/active layer/ LiF/Al cell configuration. As can be seen in Fig. 4 and Table 4, the solar cells all show very similar performance. The $V_{\text {oc }}$ remains exactly the same, in concurrence with the results obtained from square wave voltammetry. The FF and $J_{\mathrm{sc}}$ show some variation, but differences are within the margin of error as can be seen in the averages over multiple cells. This indicates very clearly that the $6 \mathrm{~T}$ segments, despite having a particularly low solubility, do not change the morphology of the layer significantly. Therefore it has to be concluded that this $6 \mathrm{~T}$ defect has no influence on the optoelectronic properties or solar cell performance in concentrations up to $5 \%$.

\subsection{Model homocoupling reactions}

In the previous sections is was established that deliberately introducing homocoupling defects exerts no consistent effect on the optical and photovoltaic properties of the resulting PDPP3T and PDPP4T polymers in concentrations up to $5 \%$ or maybe even $20 \%$. Hence, from these data it is not possible to estimate the amount of naturally occurring defect during the synthesis and the question arises how much homocoupling occurs in these Stille polymerizations. To address this question, the following experiment was conceived. A monobrominated DPP monomer, 3-(5-bromothiophen-2-yl)-2,5-bis(2-

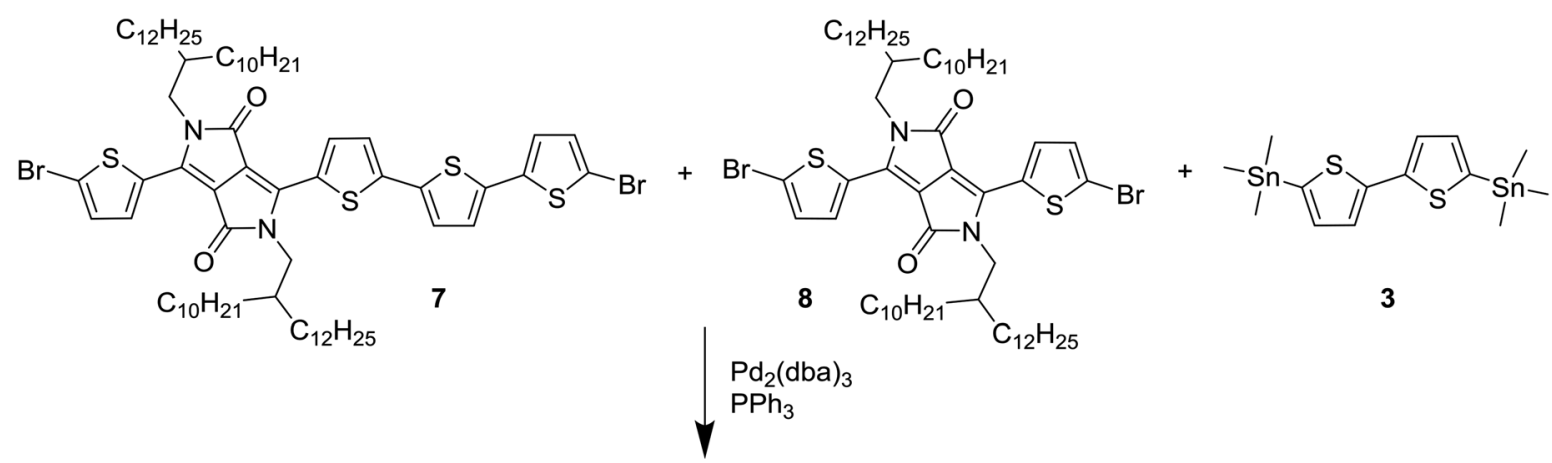

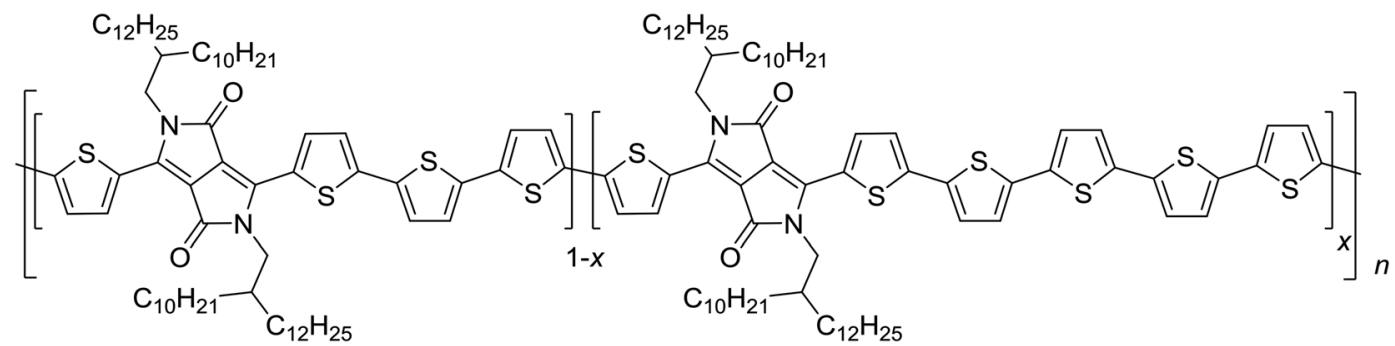

Scheme 3 Synthesis of the PDPP4T polymers with 6 T defects. The stoichiometry of the monomers 7 and 8 was altered to obtain $x=0,2$, and $5 \%$ of intentional defects. 

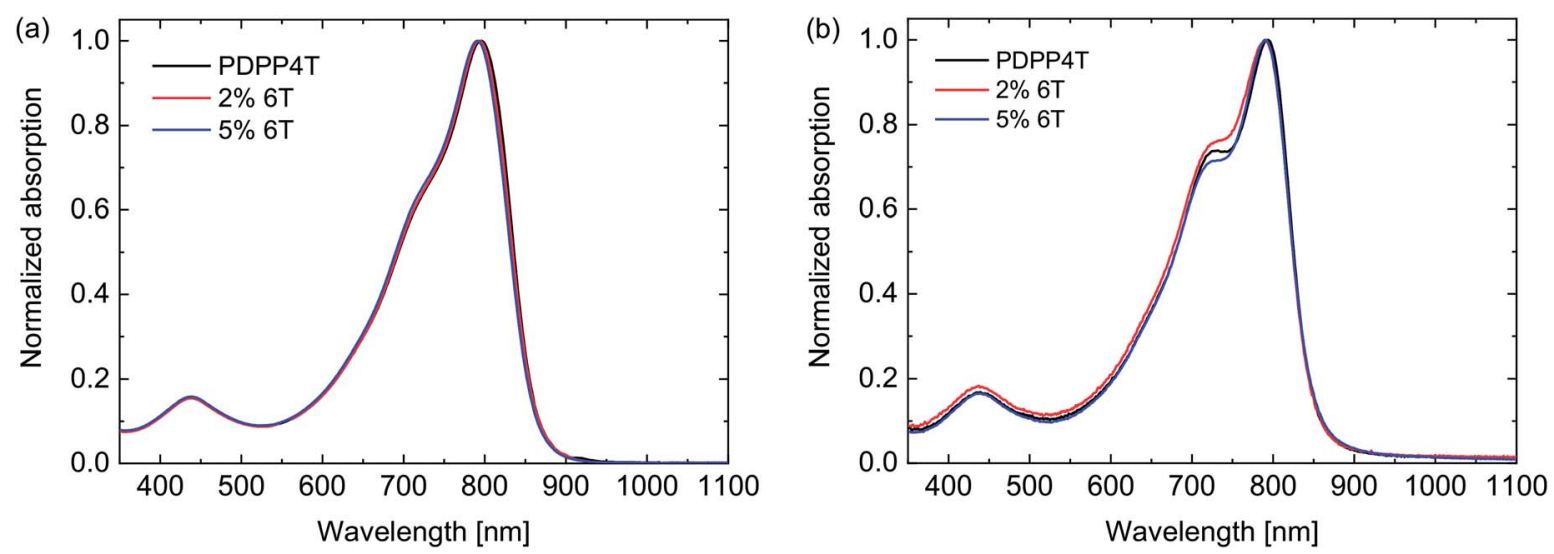

Fig. 3 UV-vis-NIR spectra of the PDPP4T polymers with 6T defects. (a) Dissolved in chloroform. (b) In thin films.

Table 3 Physical properties of the PDPP3T polymers with 6T defects Polymer $M_{\mathrm{n}}[\mathrm{kDa}] M_{\mathrm{w}}[\mathrm{kDa}] Ð \quad E_{\mathrm{g}, \mathrm{opt}}[\mathrm{eV}] \mathrm{HOMO}^{a}[\mathrm{eV}] \mathrm{LUMO}^{a}[\mathrm{eV}]$

\begin{tabular}{lllllll}
\hline PDPP4T & 83 & 150 & 1.8 & 1.46 & -5.13 & -3.26 \\
$2 \% 6$ T & 79 & 150 & 1.9 & 1.47 & -5.13 & -3.26 \\
$5 \% 6$ T & 79 & 144 & 1.8 & 1.46 & -5.13 & -3.25
\end{tabular}

${ }^{a}$ Determined with square wave voltammetry $v s . \mathrm{Fc} / \mathrm{Fc}^{+}$, which was set at $-4.8 \mathrm{eV}$ vs. vacuum.

decyltetradecyl)-6-(thiophen-2-yl)-2,5-dihydropyrrolo[3,4-c] pyrrole-1,4-dione (4), was reacted with 5,5'-bis(trimethylstannyl)-2,2'-bithiophene (3) (Scheme 4). The mixture of reactants was prepared and dissolved before being separated in three flasks. One flask was treated in the same way as Stille polymerizations are usually conducted: $1.5 \%$ of tris(dibenzylideneacetone)dipalladium $(0)\left(\mathrm{Pd}_{2}(\mathrm{dba})_{3}\right)$ and $6 \%$ of triphenylphosphine $\left(\mathrm{PPh}_{3}\right)$ were added before being degassed with argon, sealed, and heated. Another flask was subjected to the same treatment except that it was not degassed, and ambient air was allowed to remain in the flask. This was considered as a simulation of an error or oversight during normal polymerization. To the last flask $3 \%$ of bis(triphenylphosphine)palladium(II) dichloride $\left(\mathrm{Pd}_{2}\left(\mathrm{PPh}_{3}\right)_{2} \mathrm{Cl}_{2}\right)$ was added as a catalyst, before the mixture was degassed with argon, sealed, and heated. This was used as a reference, as the presence of $3 \%$ of $\operatorname{Pd}(\mathrm{II})$ should cause around $3 \%$ of homocoupling defect if all $\mathrm{Pd}($ II) is converted to $\operatorname{Pd}(0)$.

All reactions were left overnight and the crude products were isolated without any purification. MALDI-TOF-MS was then used to investigate the composition of the product mixtures.

Table 4 Photovoltaic performance of the PDPP4T polymers ${ }^{a}$

\begin{tabular}{llllll}
\hline Polymer & $M_{\mathrm{n}}[\mathrm{kDa}]$ & $J_{\mathrm{sc}}\left[\mathrm{mA} \mathrm{cm}^{-2}\right]$ & $V_{\mathrm{oc}}[\mathrm{V}]$ & $\mathrm{FF}$ & PCE [\%] \\
\hline PDPP4T & 83 & $15.3(15.2)$ & $0.64(0.64)$ & $0.69(0.66)$ & $6.8(6.4)$ \\
2\% 6T & 79 & $15.4(15.0)$ & $0.64(0.64)$ & $0.66(0.66)$ & $6.5(6.3)$ \\
$5 \% 6 \mathrm{~T}$ & 79 & $15.0(14.8)$ & $0.65(0.64)$ & $0.66(0.66)$ & $6.5(6.3)$
\end{tabular}

${ }^{a}$ Best cells are shown, numbers between parentheses refer to the average over 4 cells.
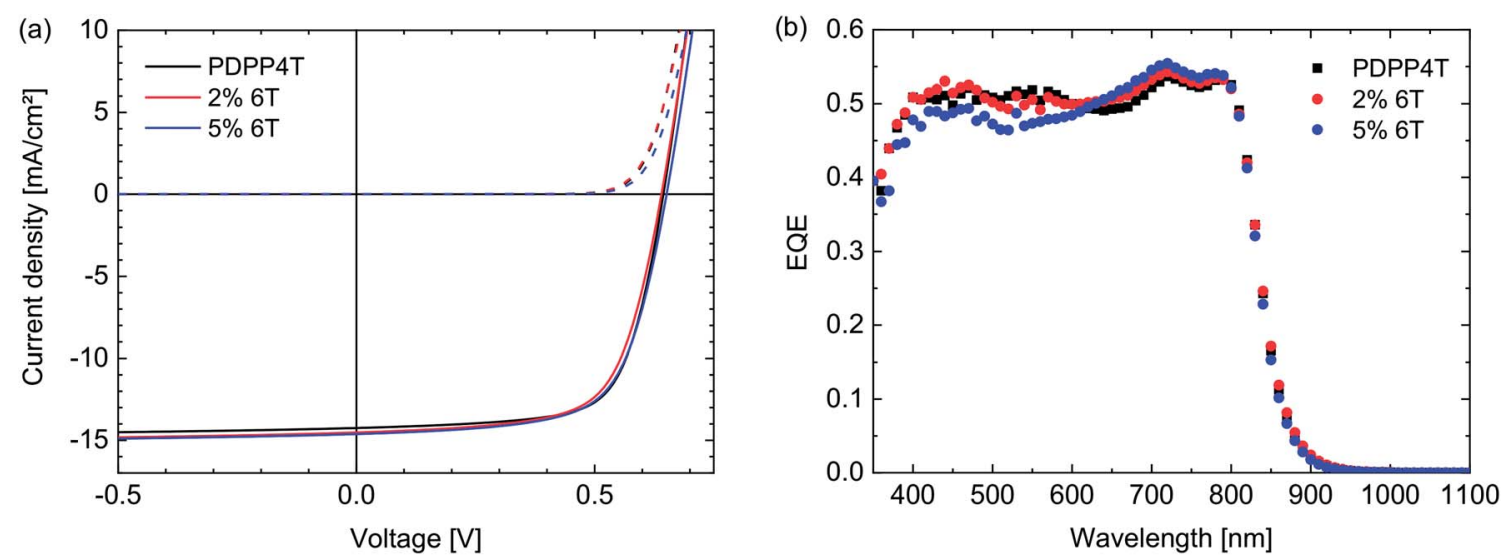

Fig. 4 (a) J-V-characteristics of PDPP4T : [70]PCBM (1:2 w/w) polymer solar cells in which the PDPP4T polymers contain 6T defects (see legends). (b) Corresponding EQE spectra. 


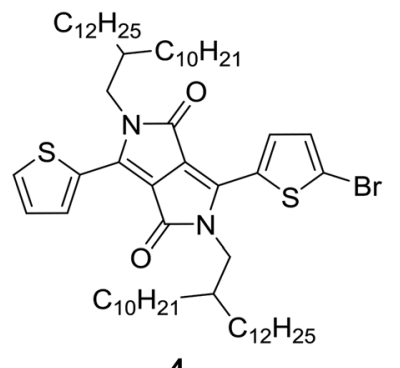

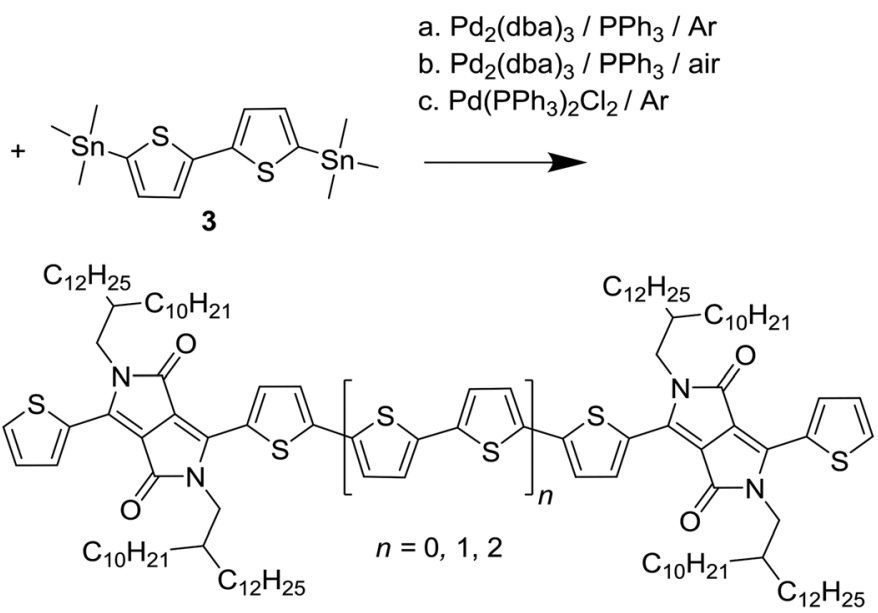

Scheme 4 Model homocoupling Stille reaction under three different catalytic conditions. The main product is $n=1$. Homocoupling of 4 will result in the product with $n=0$, while homocoupling of 3 and subsequent reactions with 4 will result in the product with $n=2$.
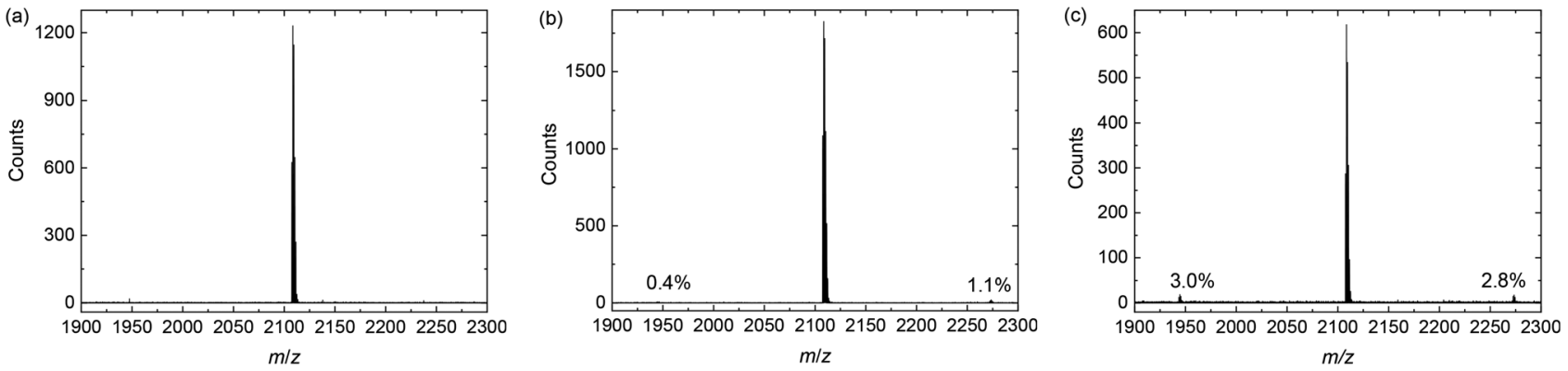

Fig. 5 MALDI-TOF-MS of the homocoupling model reaction mixtures (Scheme 4). (a) With standard conditions. (b) With air. (c) With Pd(I).

Fig. 5c shows that in the case of the reaction with $\mathrm{Pd}(\mathrm{II})$ as catalyst, the main peak, belonging to the product with four thiophene rings between DPP cores $(n=1, m / z=2107 \mathrm{amu})$, is flanked by peaks at 2271 and 1943 amu. These peaks correspond to the products with $\operatorname{six}(n=2)$ and two $(n=0)$ thiophene rings in between the DPP moieties. Assuming that the ionization efficiency of these three species is the same, which is likely due to their similar chemical structures, the intensity of the peaks relative to the main peak can indicate the concentration of these species. The relative intensity of the $6 \mathrm{~T}$ product is $2.8 \%$ (a)

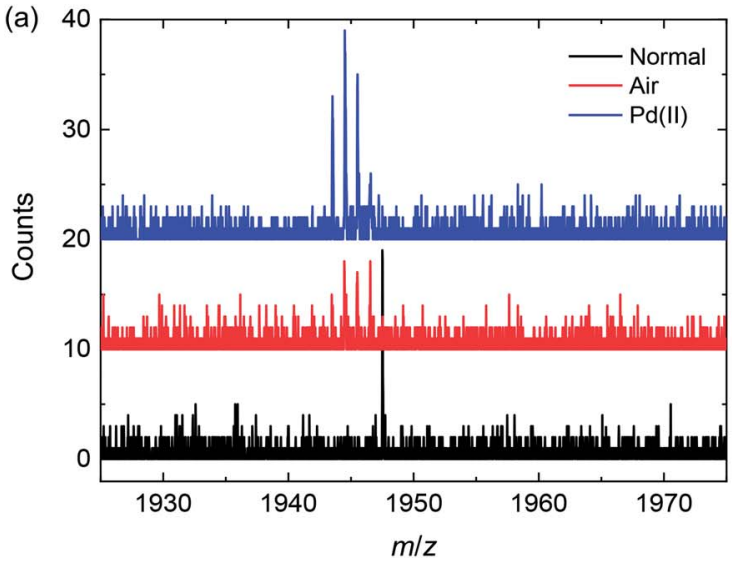

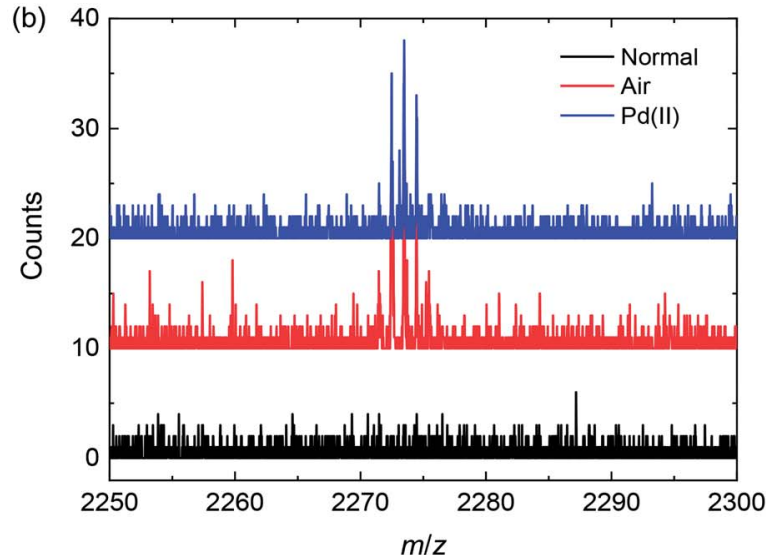

Fig. 6 Detail of the MALDI-TOF mass spectra of the three mixtures, showing the peaks corresponding to the product with two central thiophene rings ( $n=0$ in Scheme 4) (left) and the product with six central thiophene rings ( $n=2$ in Scheme 4) (right). 
is due to homocoupling of $\mathbf{3}$ and in good agreement with the expected value of $3 \%$ when all $\operatorname{Pd}(\mathrm{II})$ catalyst is reduced to $\operatorname{Pd}(0)$. The $2 \mathrm{~T}$ product, which is the result of homocoupling of (4), is present in $3.0 \%$ relative intensity. The presence of this product is slightly unexpected but possibly due to the age of the catalyst.

Repeating this analysis for the degassed sample and $\operatorname{Pd}(0)$ catalyst (Fig. 5a), it is clear that no homocoupling of any kind can be detected above the noise level. This indicates that if any homocoupling is present in this sample, its relative concentration is under $0.5 \%$. For the $\operatorname{Pd}(0)$ catalyzed reaction exposed to ambient air (Fig. 5b), both kinds of homocoupling can be detected: $1.1 \%$ of the trialkylstannyl-based homocoupling product ( $n=2$ in Scheme 4 ) is present, which suggests that oxidation of palladium can occur when the reaction mixture is exposed to air. Also, $0.4 \%$ of the bromide-based homocoupling ( $n=0$ in Scheme 1) can be observed, indicating that exposure to air can also influence this coupling mechanism. This is possibly due to oxidation of the triphenylphosphine ligand, leading to an imbalance in the ligand to palladium ratio, which was proven before to have an effect on this type of homocoupling. ${ }^{16}$ Fig. 6 shows details of the MALDI-TOF mass spectra in the region where homocoupling products $n=0$ and $n=2$ are expected.

\section{Conclusion}

By deliberately creating defects in the monomers of donoracceptor DPP polymers, we investigated the effect of homocoupling reactions between two organometallic trialkylstannyl monomers in palladium-catalyzed cross-coupling polymerization reactions. In the case of PDPP3T, the $4 \mathrm{~T}$ defects that were introduced seemed to have little effect on the optoelectronic properties of the resulting materials. Also in solar cells no consistent effect of the homocoupling defects on the photovoltaic performance was observed, even though the defectcontaining polymers generally gave a reduced performance as a result of a lower short-circuit current density than the defectfree polymers of comparable molecular weight. In all cases open-circuit voltage and fill factor were identical. The variation in short-circuit current density is not uncommon for different batches of the same polymer and can result from variations in molecular weight and polydispersity, which often affect the nanomorphology, or from other factors such as the presence of impurities. The results suggests that even for large concentrations (at least up to 10\%), the effects of these defects are smaller than common batch-to-batch variations. In the case of PDPP4T, the $6 \mathrm{~T}$ defects also did not have any measurable effect on the energy levels of the polymer. The solar cells all showed very similar performance, thus excluding that the 6T segments had any large effect on the morphology of the layer.

With a model reaction, the naturally occurring amount of homocoupling during a Stille reaction was investigated. It was found that under optimum reaction conditions no homocoupling of trialkylstannyl monomers could be detected and that the level of defects is therefore below $0.5 \%$. This validates the experiments with the intentionally introduced defects, by confirming that the naturally occurring defect level is far below the amounts that were deliberately added to the polymers. It was also found that exposure to air could induce $1.1 \%$ of homocoupling defects, thus confirming that this side reaction could easily take place if mistakes or inaccuracies occur during the polymerization reaction. Interestingly, also $0.4 \%$ homocoupling of the bromide monomer was detected, indicating that air exposure could also influence this side-reaction.

In previous work we have shown that in the case of homocoupling of dibromide monomers (Br-T-DPP-T-Br) in the synthesis of DPP polymers, the resulting T-DPP-2T-DPP-T defects have a lower band gap and constitute traps for excitons and charges. In contrast, in organometallic-based homocoupling of bis(trialkylstannyl) monomers (Sn- $n \mathrm{~T}-\mathrm{Sn})$, the DPP units in the resulting DPP-T-2nT-T-DPP chain defects will be further apart. Hence their interaction is weakened, such that these defects will not give rise to traps in the same way. This was confirmed by the defect-containing polymers because even with $20 \%$ of defects no change in the optoelectronic properties or the $V_{\text {oc }}$ could be observed. As it is clear from the PDPP4T polymers that homocoupling defects, even $6 \mathrm{~T}$ segments with significantly lower solubility, up to $5 \%$ are unlikely to have a significant impact on morphology, the conclusion must be that these homocoupling defects can be ignored when assessing the photovoltaic performance of these DPP polymers. We emphasize that this is not a general conclusion, but depends on the actual chemical structure of the polymer main chain and the precise nature of the defect. As an example, if the functional groups on the reaction components would be inverted, i.e. a DPP unit incorporated in the bis(trialkylstannyl) monomer in a polymerization reaction with dibromodithiophene, the defect resulting from organometallic-based homocoupling will have a large impact on the performance of the resulting PDPP4T. Also, Sommer et al. established a large impact of carbazole homocoupling on the photovoltaic performance in PCDTBT polymers with [70]PCBM..$^{23}$ Sommer et al. showed that mainly the $J_{\mathrm{SC}}$ and $\mathrm{FF}$ are affected, while the $V_{\mathrm{OC}}$ remained essentially unchanged. The exact reason could not be identified. In PCDTBT, the carbazole units bear 1-octylnonyl sidechains. Hence homocoupling of the carbazoles could increase the solubility of the polymers and give rise to an unfavorable more mixed morphology. ${ }^{3}$

Summarizing, defects that can be associated with homocoupled trialkylstannyl thiophene monomers do not give rise to significant change of the opto-electronic properties of DPP based polymers PDPP3T and PDPP4T. Moreover, using the optimized synthesis protocol for DPP polymers, we find no evidence of significant homocoupling of any kind. We stress that this conclusion holds for the specific cases investigated and that for other donor-acceptor polymers the result could be different.

\section{Experimental section}

\subsection{Materials and methods}

Unless indicated otherwise, all synthetic procedures were performed under a protective argon atmosphere. Commercial (dry) solvents and reactants were used without further purification, unless stated otherwise. $N$-bromosuccinimide (NBS) was 
recrystallized from deionized water prior to use. 2,5-Bis(trimethylstannyl)thiophene (2), 5,5'-bis(trimethylstannyl)-2,2'bithiophene (3), and triphenylphosphine $\left(\mathrm{PPh}_{3}\right)$ were recrystallized from methanol prior to polymerization. Tris(dibenzylideneacetone)dipalladium $\quad\left(\mathrm{Pd}_{2}(\mathrm{dba})_{3}\right) \quad$ and bis(triphenylphosphine)palladium(II) dichloride $\left(\mathrm{Pd}\left(\mathrm{PPh}_{3}\right)_{2} \mathrm{Cl}_{2}\right)$ were purchased from Strem Chemicals, Inc., [70]PCBM (purity 90-95\%) was purchased from Solenne BV. All other chemicals and solvents were obtained from Sigma-Aldrich Co. 3,6-Bis(5bromothiophen-2-yl)-2,5-bis(2-hexyldecyl)-2,5-pyrrolo[3,4-c]

pyrrole-1,4-dione (1), ${ }^{26} \quad 3$-(5-bromothiophen-2-yl)-2,5-bis(2decyltetradecyl)-6-(thiophen-2-yl)-2,5-pyrrolo[3,4-c]pyrrole-1,4dione (4), ${ }^{27}$ and 3,6-bis(5-bromothiophen-2-yl)-2,5-bis(2-decyltetradecyl)-2,5-pyrrolo[3,4-c]pyrrole-1,4-dione $(\mathbf{8})^{28}$ were synthesized according to previously published procedures.

${ }^{1} \mathrm{H}-\mathrm{NMR}$ (400 MHz) spectra were recorded on a Varian Mercury spectrometer. Chemical shifts are given in ppm with respect to tetramethylsilane as internal standard. Matrix assisted laser desorption ionization time of flight (MALDI-TOF) mass spectrometry was measured on a Bruker Autoflex Speed spectrometer. For the analysis of the model homocoupling reaction, trans-2-[3-(4-tert-butylphenyl)-2-methyl-2-propenylidene]

malononitrile (DCTB) was used as matrix for all samples. Polymer molecular-weight distributions were estimated by GPC at $140{ }^{\circ} \mathrm{C}$ on a PL-GPC 120 system using a PL-GEL $10 \mathrm{~mm}$ MIXED-C column with 1,2-dichlorobenzene (o-DCB) as the eluent and using polystyrene internal standards. Samples were dissolved at a concentration of $0.1 \mathrm{mg} \mathrm{ml}^{-1}$ in $o$-DCB at $140{ }^{\circ} \mathrm{C}$ for $1 \mathrm{~h}$ before being measured.

UV-vis-NIR absorption spectroscopy was conducted on a PerkinElmer Lambda 1050 spectrophotometer with a 3D WB $\mathrm{PMT} / \mathrm{InGaAs} / \mathrm{PbS}$ detector module. Solid films were obtained by spin coating (2000 rpm) solutions of the materials $\left(4 \mathrm{mg} \mathrm{ml}^{-1}\right)$ in chloroform onto glass substrates which were pre-cleaned with acetone and isopropanol, before being treated with UVozone for $30 \mathrm{~min}$. Square wave voltammetry was measured on the polymers in solid state which were deposited onto a platinum wire by dipping the wire in the hot solutions (chloroform). A silver rod was employed as counter electrode and a silver chloride coated silver rod $(\mathrm{Ag} / \mathrm{AgCl})$ was used as a quasireference electrode. $0.1 \mathrm{M}$ tetrabutylammonium hexafluorophosphate in acetonitrile was used as electrolyte solution. The measurement was carried out under inert atmosphere with an AutoLab PGSTAT 12 at a scan speed of $0.125 \mathrm{~V} \mathrm{~s}^{-1}$, a modulation amplitude of $20 \mathrm{mV}$, and at a frequency of $25 \mathrm{~Hz}$. Ferrocene/ferrocenium $\left(\mathrm{Fc} / \mathrm{Fc}^{+}\right)$was employed as a standard with $E=-4.8 \mathrm{eV}$.

Photovoltaic devices with an active area of 0.09 and $0.16 \mathrm{~cm}^{2}$ were fabricated in air on patterned indium tin oxide (ITO) glass substrates (Naranjo Substrates). The substrates were cleaned by sonication in acetone for $15 \mathrm{~min}$, followed by scrubbing with a sodium dodecyl sulfate solution (99\%, Acros), rinsing with deionized water, and a final sonication step in 2-propanol. Before deposition of the device layers the substrates underwent a 30 min. UV-ozone treatment. Clevios PEDOT:PSS Al 4083 (Heraeus), was deposited by spin coating at $3000 \mathrm{rpm}$. The active layers were deposited from a solution of polymer $(4 \mathrm{mg}$ $\mathrm{ml}^{-1}$ ) and [70]PCBM (8 $\left.\mathrm{mg} \mathrm{ml}^{-1}\right)$ in chloroform containing $7.5 \%$ of $o$-DCB in the case of the PDPP3T polymers, and $10 \%$ of $o$-DCB in the case of the PDPP4T polymers. The solutions were heated to $90{ }^{\circ} \mathrm{C}$ for one hour to ensure that the polymers were completely dissolved, then kept at $60{ }^{\circ} \mathrm{C}$, and were finally cooled to room temperature under vigorous stirring during $2 \mathrm{~min}$. Before spin coating at 2000 or $3000 \mathrm{rpm}$. LiF (1 nm) and $\mathrm{Al}(100$ $\mathrm{nm})$ were deposited by thermal evaporation under high vacuum $\left(\sim 3 \times 10^{-7} \mathrm{mbar}\right)$ as a back contact.

Current density-voltage $(J-V)$ characteristics were measured with a Keithley 2400 source meter under $\sim 100 \mathrm{~mW}$ $\mathrm{cm}^{-2}$ white light illumination from a tungsten-halogen lamp filtered by a Schott GG385 UV filter and a Hoya LB120 daylight filter. The short-circuit current density $\left(J_{\mathrm{sc}}\right)$ was determined more accurately from external quantum efficiency (EQE) measurements by integration of the EQE with the AM1.5 G solar spectrum. EQE measurements were carried out under 1 sun equivalent operating conditions in a setup consisting of a modulated monochromatic light, a preamplifier (Stanford Research Systems SR570), and a lock-in amplifier (Stanford Research Systems, SR830). The modulated monochromatic light was generated by using an optical chopper (Stanford Research Systems, SR540), a monochromator (Oriel Cornerstone 130) and a $50 \mathrm{~W}$ (Osram 64610) tungsten-halogen lamp. The 1 sun conditions were provided by the use of a $730 \mathrm{~nm}$ light-emitting diode (Thorlabs) at different intensities for appropriate bias illumination. The devices were kept in a nitrogen-filled box with a quartz window. A calibrated silicon cell was used as reference for $J-V$ and EQE measurements.

\subsection{Synthesis}

General polymerization procedure for the PDPP3T polymers. 3,6-Bis(5-bromothiophen-2-yl)-2,5-bis(2-hexyldecyl)-2,5-pyrrolo [3,4-c]pyrrole-1,4-dione (1) (1 eq.) was loaded together with 2,5bis(trimethylstannyl)thiophene (2) and 5,5'-bis(trimethylstannyl)-2,2'-bithiophene (3) (together 1 eq.) in a Schlenk tube containing tris(dibenzylideneacetone)dipalladium $(1.5 \%)$ and triphenylphosphine (6\%). The solids were placed under argon before being dissolved in a mixture of toluene and dimethylformamide (DMF) $(9: 1)$. The mixture was degassed with argon for $15 \mathrm{~min}$. And then sealed in the tube for reaction at $115{ }^{\circ} \mathrm{C}$ overnight. 1,1,2,2-Tetrachloroethane (TCE) was then added to dissolve and dilute the mixture before it was precipitated in methanol. The solids were then filtered, dissolved in TCE at $110{ }^{\circ} \mathrm{C}$ and stirred with ethylenediaminetetraacetic acid (EDTA) for one hour after which water was added and the mixture was stirred for another hour. The organic layer was then separated, washed twice with water and partially reduced in volume under reduced pressure. The polymer was then precipitated in methanol and the solids were subjected to Soxhlet extraction with subsequently acetone, hexane, and dichloromethane. The remaining solids were then dissolved in TCE, the solution was filtered and precipitated in acetone. The polymers were then filtered and dried at $40{ }^{\circ} \mathrm{C}$ in vacuum overnight. 
PDPP3T (5\% 4T). The general procedure was followed with 3,6-bis(5-bromothiophen-2-yl)-2,5-bis(2-hexyldecyl)-2,5-pyrrolo [3,4-c]pyrrole-1,4-dione (1) (70 mg, $77.2 \mu \mathrm{mol}, 1$ eq.), 2,5-bis(trimethylstannyl)thiophene (2) (30 mg, $73.3 \mu \mathrm{mol}, 0.95$ eq.), 5,5'-bis(trimethylstannyl)-2,2'-bithiophene (3) (1.9 mg, 3.9 $\mu \mathrm{mol}, \quad 0.05 \quad$ eq.), tris(dibenzylideneacetone)dipalladium (1.066 mg, $1.16 \mu \mathrm{mol}, 1.5 \%$ ), and triphenylphosphine (1.215 mg, $4.63 \mu \mathrm{mol}, 6 \%)$ in toluene/DMF (9:1) (1.5 ml). GPC $\left(o\right.$-DCB, $\left.140{ }^{\circ} \mathrm{C}\right): M_{\mathrm{n}}=148 \mathrm{kDa}, M_{\mathrm{w}}=399 \mathrm{kDa}, \emptyset=2.7$.

PDPP3T (10\% 4T). The general procedure was followed with 3,6-bis(5-bromothiophen-2-yl)-2,5-bis(2-hexyldecyl)-2,5pyrrolo[3,4-c]pyrrole-1,4-dione (1) (70 mg, $77.2 \mu \mathrm{mol}, 1$ eq.), 2,5-bis(trimethylstannyl)thiophene (2) $(28.5 \mathrm{mg}, 69.5 \mu \mathrm{mol}$, 0.90 eq.), 5,5'-bis(trimethylstannyl)-2,2'-bithiophene (3) (3.8 mg, $7.7 \mu \mathrm{mol}, 0.10$ eq.), tris(dibenzylideneacetone) dipalladium (1.066 mg, $1.16 \mu \mathrm{mol}, 1.5 \%)$, and triphenylphosphine (1.215 mg, $4.63 \mu \mathrm{mol}, 6 \%)$ in toluene/DMF (9:1) $(1.5 \mathrm{ml}) . \mathrm{GPC}\left(o-\mathrm{DCB}, 140{ }^{\circ} \mathrm{C}\right): M_{\mathrm{n}}=123 \mathrm{kDa}, M_{\mathrm{w}}=330 \mathrm{kDa}, \emptyset$ $=2.7$.

PDPP3T (20\% 4T). The general procedure was followed with of 3,6-bis(5-bromothiophen-2-yl)-2,5-bis(2-hexyldecyl)2,5-pyrrolo[3,4-c]pyrrole-1,4-dione (1) (70 mg, $77.2 \mu \mathrm{mol}, 1$ eq.), 2,5-bis(trimethylstannyl)thiophene (2) (25.3 mg, 61.7 $\mu$ mol, 0.80 eq.), 5,5'-bis(trimethylstannyl)-2,2'-bithiophene (3) (7.6 mg, $15.4 \mu \mathrm{mol}, 0.20$ eq.), tris(dibenzylideneacetone) dipalladium (1.066 mg, $1.16 \mu \mathrm{mol}, 1.5 \%)$, and triphenylphosphine $(1.215 \mathrm{mg}, 4.63 \mu \mathrm{mol}, 6 \%)$ in toluene/DMF (9:1) $(1.5 \mathrm{ml})$. GPC $\left(o-\mathrm{DCB}, 140{ }^{\circ} \mathrm{C}\right): M_{\mathrm{n}}=148 \mathrm{kDa}, M_{\mathrm{w}}=399 \mathrm{kDa}, \nexists$ $=2.7$.

3-([2,2':5' $2^{\prime \prime}$-Terthiophen]-5-yl)-2,5-bis(2-decyltetradecyl)-6(thiophen-2-yl)-2,5-pyrrolo[3,4-c]pyrrole-1,4-dione (6). 3-(5-Bromothiophen-2-yl)-2,5-bis(2-decyltetradecyl)-6-(thiophen-2yl)-2,5-pyrrolo[3,4-c]pyrrole-1,4-dione (4) (150 mg, $143 \mu \mathrm{mol})$, 2-([2,2'-bithiophen]-5-yl)-4,4,5,5-tetramethyl-1,3,2-

dioxaborolane (5) $(62.5 \mathrm{mg}, 214 \mu \mathrm{mol})$, tris(dibenzylideneacetone)dipalladium $(1.96 \mathrm{mg}, 2.14 \mu \mathrm{mol})$, and triphenylphosphine $(2.24 \mathrm{mg}, 8.55 \mu \mathrm{mol})$ were placed in a Schlenk tube and put under argon. Then toluene $(2 \mathrm{ml})$ was added and the mixture was degassed for $15 \mathrm{~min}$. Before a previously degassed $2 \mathrm{M} \mathrm{K}_{3} \mathrm{PO}_{4}$ solution in water $(0.36 \mathrm{ml})$ was added along with 1 drop of Aliquad 336. The tube was then sealed and heated to $115{ }^{\circ} \mathrm{C}$ and left to react overnight. The reaction mixture was then left to cool before being diluted with dichloromethane and extracted with water. Column chromatography was then performed (7:3 heptane : dichloromethane, gradient to $5: 5$ ) and the obtained solid was recrystallized in methanol to yield the product as a blue solid (78 mg, yield 48\%). ${ }^{1} \mathrm{H}$ NMR (400 $\left.\mathrm{MHz} \mathrm{CDCl}_{3}\right) \delta: 8.92(\mathrm{~d}, J=$ $4.2 \mathrm{~Hz}, 1 \mathrm{H}), 8.87(\mathrm{dd}, J=3.9,1.2 \mathrm{~Hz}, 1 \mathrm{H}), 7.61(\mathrm{dd}, J=5.0$, $1.2 \mathrm{~Hz}, 1 \mathrm{H}), 7.30(\mathrm{~d}, J=4.2 \mathrm{~Hz}, 1 \mathrm{H}), 7.26(\mathrm{~m}, 2 \mathrm{H}), 7.22(\mathrm{~m}$, $2 \mathrm{H}), 7.13(\mathrm{~d}, J=3.9 \mathrm{~Hz}, 1 \mathrm{H}), 7.05(\mathrm{dd}, J=5.1,3.6 \mathrm{~Hz}, 1 \mathrm{H}), 4.03$ $(\mathrm{d}, J=7.6 \mathrm{~Hz}, 4 \mathrm{H}), 1.94(\mathrm{~m}, 2 \mathrm{H}), 1.40-1.11(\mathrm{~m}, 80 \mathrm{H}), 0.87(\mathrm{td}, J$ $=6.3,3.3 \mathrm{~Hz}, 12 \mathrm{H})$.

3-(5"'-Bromo-[2,2':5', $2^{\prime \prime}$-terthiophene]-5-yl)-6-(5-bromothiophen-2-yl)-2,5-bis(2-decyltetradecyl)-2,5-pyrrolo[3,4-c]pyrrole-

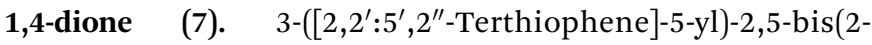

decyltetradecyl)-6-(thiophen-2-yl)-2,5-pyrrolo[3,4-c]pyrrole1,4-dione (6) (65 mg, $58 \mu \mathrm{mol})$ was dissolved of chloroform (2 $\mathrm{ml}$ ) and cooled to $0{ }^{\circ} \mathrm{C}$. $\mathrm{N}$-Bromosuccinimide (14 mg, 119 $\mu \mathrm{mol})$ was then added in 3 portions, before the mixture was allowed to warm up to room temperature and left to react overnight. To achieve full conversion, $1 \mathrm{mg}$ of $\mathrm{N}$-bromosuccinimide and later another $2 \mathrm{mg}$ were added and allowed to react for $2 \mathrm{~h}$. The mixture was then extracted with water, dried over $\mathrm{MgSO}_{4}$, and the solvents were evaporated under reduced pressure. The solids were purified via column chromatography (4:6 heptane : dichloromethane, gradient to $5: 5$ ) and recrystallized three times from methanol and once from acetone to achieve maximum purity. The product was isolated as a blue solid (30 mg, yield 40\%). ${ }^{1} \mathrm{H} \mathrm{NMR}(400 \mathrm{MHz}$, $\left.\mathrm{CDCl}_{3}\right) \delta: 8.92(\mathrm{~d}, J=4.2 \mathrm{~Hz}, 1 \mathrm{H}), 8.62(\mathrm{~d}, J=4.2 \mathrm{~Hz}, 1 \mathrm{H}), 7.30$ $(\mathrm{d}, J=4.1 \mathrm{~Hz}, 1 \mathrm{H}), 7.22(\mathrm{~d}, J=4.0 \mathrm{~Hz}, 2 \mathrm{H}), 7.06(\mathrm{~d}, J=3.8 \mathrm{~Hz}$, $1 \mathrm{H}), 7.00(\mathrm{~d}, J=3.9 \mathrm{~Hz}, 1 \mathrm{H}), 6.96(\mathrm{~d}, J=3.8 \mathrm{~Hz}, 1 \mathrm{H}), 4.02(\mathrm{~d}, J$ $=7.6 \mathrm{~Hz}, 2 \mathrm{H}), 3.95(\mathrm{~d}, J=7.7 \mathrm{~Hz}, 2 \mathrm{H}), 1.94(\mathrm{~m}, 2 \mathrm{H}), 1.40-1.15$ (m, 80H), 0.91-0.82 (m, 12H). MALDI-TOF-MS: predicted: 1292.55, found: 1292.58 .

General polymerization procedure for the PDPP4T polymers. 3,6-Bis(5-bromothiophen-2-yl)-2,5-bis(2-decyltetradecyl)-2,5pyrrolo[3,4-c]pyrrole-1,4-dione (8) and 3-(5"-Bromo$\left[2,2^{\prime}: 5^{\prime}, 2^{\prime \prime}\right.$-terthiophene]-5-yl)-6-(5-bromothiophen-2-yl)-2,5bis(2-decyltetradecyl)- 2,5-pyrrolo[3,4-c]pyrrole-1,4-dione (7) (together 1 eq.) were loaded with 5,5'-bis(trimethylstannyl)2,2'-bithiophene (3) (1 eq.) in a Schlenk tube together with tris(dibenzylideneacetone)dipalladium (1.5\%) and triphenylphosphine $(6 \%)$. The solids were placed under argon before being dissolved in a mixture of toluene and DMF $(9: 1)$. The mixture was degassed with argon for $15 \mathrm{~min}$. And then sealed in the tube for reaction at $115{ }^{\circ} \mathrm{C}$ overnight. TCE was then added to dissolve and dilute the mixture before being precipitated in methanol. The solids were then filtered, dissolved in TCE at $110{ }^{\circ} \mathrm{C}$, and stirred with EDTA for one hour after which water was added and the mixture was stirred for another hour. The organic layer was then separated, washed twice with water, and partially reduced in volume under reduced pressure. The polymer was then precipitated in methanol and the solids were subjected to Soxhlet extraction with subsequently acetone, hexane, and dichloromethane. The remaining solids were then dissolved in TCE, the solution was filtered and precipitated in acetone. The polymers were then filtered and dried at $40{ }^{\circ} \mathrm{C}$ in vacuum overnight.

PDPP4T (0\% 6T). The general procedure was followed with 3,6-bis(5-bromothiophen-2-yl)-2,5-bis(2-decyltetradecyl)-2,5pyrrolo[3,4-c]pyrrole-1,4-dione (8) (70.2 mg, $62 \mu \mathrm{mol}, 1$ eq.),

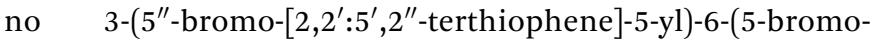
thiophen-2-yl)-2,5-bis(2-decyltetradecyl)-2,5-pyrrolo[3,4-c]

pyrrole-1,4-dione (7) (0 eq.), 5,5'-bis(trimethylstannyl)-2,2'bithiophene (3) (30.5 mg, $62 \mu \mathrm{mol}, 1$ eq.), tris(dibenzylideneacetone)dipalladium ( $0.85 \mathrm{mg}, 9.3 \mu \mathrm{mol}, 1.5 \%)$, and triphenylphosphine (0.98 mg, $3.7 \mu \mathrm{mol}, 6 \%$ ). GPC (o-DCB, 140 $\left.{ }^{\circ} \mathrm{C}\right): M_{\mathrm{n}}=83 \mathrm{kDa}, M_{\mathrm{w}}=150 \mathrm{kDa}, \emptyset=1.8$.

PDPP4T (2\% 6T). The general procedure was followed with 3,6-bis(5-bromothiophen-2-yl)-2,5-bis(2-decyltetradecyl)-2,5- 
pyrrolo[3,4-c]pyrrole-1,4-dione (8) (68.7 mg, $60.8 \mu \mathrm{mol}, 0.98$ eq.),


2-yl)-2,5-bis(2-decyltetradecyl)-2,5-pyrrolo[3,4-c]pyrrole-1,4dione (7) (1.61 mg, $1.2 \mu \mathrm{mol}, 0.02$ eq.), 5,5'-bis(trimethylstannyl)-2,2'-bithiophene (3) (30.5 mg, $62 \mu \mathrm{mol}, 1$ eq.), tris(dibenzylideneacetone)dipalladium $(0.85 \mathrm{mg}, 9.3 \mu \mathrm{mol}, 1.5 \%)$ and triphenylphosphine $(0.98 \mathrm{mg}, 3.7 \mu \mathrm{mol}, 6 \%)$. GPC (o-DCB, 140 $\left.{ }^{\circ} \mathrm{C}\right): M_{\mathrm{n}}=79 \mathrm{kDa}, M_{\mathrm{w}}=150 \mathrm{kDa}, Ð=1.9$.

PDPP4T (5\% 6T). The general procedure was followed with 3,6-bis(5-bromothiophen-2-yl)-2,5-bis(2-decyltetradecyl)-2,5-pyrrolo[3,4-c]pyrrole-1,4-dione (8) (66.6 mg, $58.9 \mu \mathrm{mol}, 0.95$ eq.), 3(5"-bromo-[2,2':5',2" -terthiophene]-5-yl)-6-(5-bromothiophen-2yl)-2,5-bis(2-decyltetradecyl)-2,5-pyrrolo[3,4-c]pyrrole-1,4-dione (7) (4.0 mg, $3.1 \mu \mathrm{mol}, 0.05$ eq.), 5,5'-bis(trimethylstannyl)-2,2'bithiophene (3) $(30.5 \mathrm{mg}, 62 \mu \mathrm{mol}, 1 \mathrm{eq}$.), of tris(dibenzylideneacetone)dipalladium $(0.85 \mathrm{mg}, 9.3 \mu \mathrm{mol}, 1.5 \%)$ and triphenylphosphine (0.98 mg, $3.7 \mu \mathrm{mol}, 6 \%)$. GPC $\left(o-\mathrm{DCB}, 140{ }^{\circ} \mathrm{C}\right): M_{\mathrm{n}}$ $=79 \mathrm{kDa}, M_{\mathrm{w}}=144 \mathrm{kDa}, \emptyset=1.8$.

Model homocoupling reaction. 3-(5-Bromothiophen-2-yl)2,5-bis(2-decyltetradecyl)-6-(thiophen-2-yl)-2,5-pyrrolo[3,4-c] pyrrole-1,4-dione (150 mg, $143 \mu \mathrm{mol})$ (4) and 5,5'-bis(trimethylstannyl)-2,2'-bithiophene (3) (35 mg, $71 \mu \mathrm{mol})$ were weighed and dissolved in a mixture of dry toluene $(2.7 \mathrm{ml})$ and dry DMF $(0.3 \mathrm{ml})$. The mixture was then separated in three equal parts $(1 \mathrm{ml})$. To the first reaction mixture, tris(dibenzylideneacetone)dipalladium $(0.33 \mathrm{mg}, 3.56 \mu \mathrm{mol})$ and triphenylphosphine $(0.37 \mathrm{mg}, 14.3 \mu \mathrm{mol})$ were added. The mixture was then degassed with argon for $15 \mathrm{~min}$, before being sealed and heated to $115{ }^{\circ} \mathrm{C}$ overnight. The solvents were then removed under reduced pressure and the solids were analyzed without further purification. To the second reaction mixture, tris(dibenzylideneacetone)dipalladium (0.33 mg, $3.56 \mu \mathrm{mol})$ and triphenylphosphine $(0.37 \mathrm{mg}, 14.3$ $\mu \mathrm{mol})$ were added. The mixture was left in air and sealed with air in the flask before being heated to $115{ }^{\circ} \mathrm{C}$ overnight. The solvents were then removed under reduced pressure and the solids were analyzed without further purification. To the third reaction mixture, bis(triphenylphosphine)palladium(II) dichloride $(0.50 \mathrm{mg}, 7.13 \mu \mathrm{mol})$ was added. The mixture was then degassed with argon for $15 \mathrm{~min}$, before being sealed and heated to $115{ }^{\circ} \mathrm{C}$ overnight. The solvents were then removed under reduced pressure and the solids were analyzed without further purification.

\section{Conflicts of interest}

There are no conflicts to declare.

\section{Acknowledgements}

We thank Dr Koen Hendriks for valuable discussions. G. H. L. Heintges acknowledges the Agency for Innovation by Science and Technology in Flanders (IWT). This project has further received funding from the European Research Council under the European Union's Seventh Framework Programme (FP/2007-2013)/ERC Grant Agreement No. 339031 and from the Ministry of Education, Culture and Science (Gravity program 024.001.035).

\section{References}

1 A. Katsouras, N. Gasparini, C. Koulogiannis, M. Spanos, T. Ameri, C. J. Brabec, C. L. Chocos and A. Avgeropoulos, Macromol. Rapid Commun., 2015, 36, 1778-1797.

2 K. H. Hendriks, G. H. L. Heintges, V. S. Gevaerts, M. M. Wienk and R. A. J. Janssen, Angew. Chem., Int. Ed., 2013, 52, 8341-8344.

3 J. J. van Franeker, G. H. L. Heintges, C. Schaefer, G. Portale, W. Li, M. M. Wienk, P. van der Schoot and R. A. J. Janssen, J. Am. Chem. Soc., 2015, 137, 11783-11794.

4 Z. B. Henson, K. Müllen and G. C. Bazan, Nat. Chem., 2012, 4, 699-704.

5 J. K. Park, J. Jo, J. H. Seo, J. S. Moon, Y. D. Park, K. Lee, A. J. Heeger and G. C. Bazan, Adv. Mater., 2011, 23, 24302435.

6 G. H. L. Heintges, J. J. van Franeker, M. M. Wienk and R. A. J. Janssen, Chem. Commun., 2016, 52, 92-95.

7 C. Bracher, H. Yi, N. W. Scarratt, R. Masters, A. J. Pearson, C. Rodenburg, A. Iraqi and D. G. Lidzey, Org. Electron., 2015, 27, 266-273.

8 M. P. Nikiforov, B. Lai, W. Chen, S. Chen, R. D. Schaller, J. Strzalka, J. Maser and S. B. Darling, Energy Environ. Sci., 2013, 6, 1513-1520.

9 W. R. Mateker, J. D. Douglas, C. Cabaneto, I. T. SachsQuintana, J. A. Bartelt, E. T. Hoke, A. El Labban, P. Beaujuge, J. M. J. Fréchet and M. D. McGehee, Energy Environ. Sci., 2013, 6, 2529-2537.

10 I. Osaka and R. D. McCullough, Acc. Chem. Res., 2008, 41, 1202-1214.

11 L. Ying, F. Huang and G. C. Bazan, Nat. Commun., 2017, 8, 14047.

12 F. Koch and W. Heitz, Macromol. Chem. Phys., 10097, 198, 1531-1544.

13 V. Farina, B. Krishnan, D. R. Marshall and G. P. Roth, J. Org. Chem., 1993, 58, 5434-5444.

14 F. Lombeck, H. Komber, S. I. Gorelsky and M. Sommer, ACS Macro Lett., 2014, 3, 819-823.

15 G. Pirotte, P. Verstappen, D. Vanderzande and W. Maes, Adv. Electron. Mater., 2018, 4, 1700481.

16 K. H. Hendriks, W. Li, G. H. L. Heintges, G. W. P. van Pruissen, M. M. Wienk and R. A. J. Janssen, J. Am. Chem. Soc., 2014, 136, 11128-11133.

17 W. Hong, S. Chen, B. Sun, M. A. Arnould, Y. Meng and Y. Li, Chem. Sci., 2015, 6, 3225-3235.

18 D. A. Warr, L. M. A. Perdigão, H. Pinfold, J. Blohm, D. Stringer, A. Leventis, H. Bronstein, A. Troisi and G. Costantini, Sci. Adv., 2018, 4, eaas9543.

19 S. Ostrowska, S. Rogalski, J. Lorkowski, J. Walkowiak and C. Pietraszuk, Synlett, 2018, 29, 1735-1740.

20 C. A. Contreras-Celedón, J. A. Rincón-Medina, D. MendozaRayo and L. Chacón-Garcia, Appl. Organomet. Chem., 2015, 29, 439-442.

21 H. Bohra and M. Wang, J. Mater. Chem. A, 2017, 5, 1155011571. 
22 M. Moreno-Mañas, M. Perez and R. Pleixats, J. Org. Chem., 1996, 61, 2346-2351.

23 F. Lombeck, H. Komber, D. Fazzi, D. Nava, J. Kuhlmann, D. Stegerer, K. Strassel, J. Brandt, A. Diaz, Z. Mendaza, C. Müller, W. Thiel, M. Caironi, R. Friend and M. Sommer, Adv. Energy Mater., 2016, 6, 1601232.

24 B. Carsten, F. He, H. J. Son, T. Xu and L. Yu, Chem. Rev., 2011, 111, 1493-1528.
25 W. Li, R. S. C. Roelofs, M. M. Wienk and R. A. J. Janssen, J. Am. Chem. Soc., 2012, 134, 13787-13795.

26 L. Bürgi, M. Turbiez, R. Pfeiffer, F. Bienewald, H. J. Kirner and C. Winnewisser, Adv. Mater., 2008, 20, 2217-2224.

27 E. Y. Ko, G. E. Park, D. H. Lee, H. A. Um, J. Shin, M. J. Cho and D. H. Choi, ACS Appl. Mater. Interfaces, 2015, 7, 2830328310.

28 S. Cho, J. Lee, M. H. Tong, J. H. Seo and C. Yang, Adv. Funct. Mater., 2011, 21, 1910-1916. 